Whatever the answers the ever present question remains: is what we observe in vitro a reflection of what really happens in vivo?

\section{P MiKHAILIDIS} P DANDONA

Royal Free Hospital,
London NW3 2QG

${ }^{1}$ Sinzinger H, Feigl W, Silberbauer K. Lancet 1979;

ii:469.
Ogletree ML, Lefer AM, Smith JB, Nicolaou KC.
Europ f Pharmacol 1979;56:95-103.
3est HJ, et al. Acta Biol Med Ger 1976;37:827-8.
' Saba HI, Saba SR, Blackburn CA, Hartmann RC,
Mason RG. Science 1979;205:499-501.
Gryglewsi RJ, Dembinska-Kiec A, Zmuda A,
Gryglewska T. Atherosclerosis 1978;31 :385-94. Mason RG. Science 1979;205:499-501.
6 Gryglewski RJ, Dembinska-Kiec A, Zmuda
Gryglewska T. Atherosclerosis 1978;31 :385-94.

***We sent a copy of this letter to the authors, whose reply is printed below.

SIR,-Drs Mikhailidis and Dandona ask whether the heparin used in our study may have interfered with the action of residual prostacyclin $\left(\mathrm{PGI}_{2}\right)$ on the platelet-release reaction. When we compared the extent of the release reaction in platelet-rich plasma (PRP) prepared from blood that contained 2, 10 , or 100 units of heparin/ml $(n=17)$, the mean amounts of ${ }^{3} \mathrm{H}$-serotonin released were $22 \%$ (SE of mean $\pm 3 \cdot 7$ ), $15 \%( \pm 3 \cdot 8)$, and $4 \%$ $( \pm 1.4)$ respectively. The differences in release at the three heparin levels were significant $(P<0.01)$, so heparin reduces release rather than enhances it. Another factor that suggests to us that it is unlikely that a direct interaction between heparin and $\mathrm{PGI}_{2}$ influenced the results that we obtained is the inherent instability of the latter. $\mathrm{PGI}_{2}$ in aqueous solution loses its antiaggregatory activity within 20 minutes. ${ }^{1}$ In our experiments the extent of release was determined some 90 minutes after blood had been withdrawn and it is unlikely that any $\mathrm{PGI}_{2}$ remained in the plasma after this time.

It seemed possible to us that enhanced thromboxane $\mathrm{A}_{2}$ production might account for the platelet hyperactivity observed in PRP from some individuals. Accordingly we compared the extent of release with the amount of malondialdehyde (a marker for thromboxane synthesis) that is produced when arachidonic acid is added to PRP. ${ }^{2}$ We have, however, been unable to detect any relation between the two processes.

The final factual point raised by Drs Mikhailidis and Dandona relates to the validity of using ${ }^{3} \mathrm{H}$-serotonin as a marker of endogenous serotonin and hence of the extent of the release reaction. This relies, of course, on ${ }^{3} \mathrm{H}$-serotonin being taken up into the intracellular store that contains the endogenous serotonin. We have not verified this in our own studies but Costa and Murphy ${ }^{3}$ have shown that $0 \cdot 1-1.0 \mu \mathrm{mol} / 1 \quad(0.18-1.76 \mu \mathrm{g} /$ $100 \mathrm{ml}){ }^{3} \mathrm{H}$-serotonin added to PRP is all taken up into the pool of endogenous serotonin. In our experiments we added $0.5 \mu \mathrm{mol} / 1$ $(0.88 \mu \mathrm{g} / 100 \mathrm{ml})^{3} \mathrm{H}$-serotonin to the platelet preparation.

Their final question is of crucial importance; we have repeatedly emphasised in other publications that there is no evidence which allows us to be sure that any of the aspects of platelet behaviour currently studied in vitro (aggregation, adhesion, release, $\beta$-thromboglobulin levels, platelet factor 4 , and thromboxane and prostaglandin production) are of physiological or pathological significance. The relationships between in vitro and in vivo phenomena are not yet known, nor can we be sure that agents which modify in vitro behaviour in a potentially favourable way will be antithrombotic in clinical test situations.

$S$ HEPTINSTALL Graham Mulley Patricia M TAYLOR J R A Mitchell

University Department of Medicine,

University Hospital Nottingham NG7 2UH ${ }^{1}$ Moncada S, Gryglewski R, Bunting S, Vane JR.

${ }^{2}$ Cockbill SR, Heptinstall S. F Physiol 1978;276:15-6P. ${ }^{3}$ Costa JL, Murphy DL. Life Sci 1976;18:1413-8.

\section{Hirsutism and virilisation}

SIR,-We were interested to read the review of hirsutism and virilisation (9 February, p 369). Drs Jean Ginsburg and Michael C White highlight the difficulties in the investigation and management of a complex clinical problem. However, we should like to make the following points.

The authors state that sclerocystic ovaries are a leading cause of hirsutism. While investigating a large group of female hirsute patients we have found that only $15 \%$ of them could possibly be considered to have sclerocystic ovaries by clinical and biochemical criteria and by ovarian ultrasonography. The diagnosis of sclerocystic ovaries - that is, ovaries with multiple cysts and subcapsular fibrosis-is essentially histopathological and would require ovarian biopsy, usually by laparoscopy, a procedure which is not without hazards. We agree, however, that ovarian dysfunction is the main abnormality in hirsute females. Ovarian dysfunction covers a range of diseases including sclerocystic ovaries. Since chronic anovulation is common in these conditions, ${ }^{1}$ serum luteinising hormone concentrations and serial ovarian ultrasonography are helpful screening procedures in patients with clinical features suggestive of ovarian abnormality. We are concerned that the emphasis on sclerocystic ovaries might lead to excessive and unnecessary laparoscopic examinations, especially when confirmation of sclerocystic ovaries will not substantially affect the choice of treatment.

We would contest strongly that waxing should be avoided on the face. This treatment is an excellent method of removing hair from the face, even although it epilates the down. In our experience waxing does not result in scarring. To produce scarring dermal damage has to occur and it is difficult to see how this could arise with this method. Hot waxing is not a satisfactory method of hair removal from the abdomen and legs, as it is extremely time consuming. Hot wax cannot be applied to an area larger than $5 \mathrm{~cm} \times 5 \mathrm{~cm}$ at any one time, as the wax hardens too quickly if applied to larger areas and then becomes impossible to pull off rapidly. Obviously on larger areas such as the limbs waxing would take a considerable time. There are effective "cold" wax strips which are useful for the abdomen and limbs but they are expensive and can only be used once, while the hot wax can be reused. Electrolysis can cause very unsightly scarring if performed by an inexperienced operator.

We would suggest that care is taken in the selection of a progestogen for combination with ethinyloestradiol and prednisolone. $\mathrm{D}$-norgestrel and norethisterone acetate, two of the most commonly prescribed progestogens, can significantly lower sex-hormone-binding globulin and hence increase the concentrations of unbound testosterone. ${ }^{2}$ The combination of levonorgestrel (D-norgestrel) with $30 \mu \mathrm{g}$ of ethinyloestradiol or $1 \mathrm{mg}$ norethisterone acetate with $50 \mu \mathrm{g}$ of ethinyloestradiol would appear to be appropriate choices.

JOCELYN R RENTOUL COLIN A ForRest Patricia Morley R E YOUNG

Western Infirmary,
Glasgow G11 6NT

${ }^{1}$ Yen SSC. Clin Endocrin 1980;2:177-208. 2 El Makhzangy MN, Wynn V, Lawrence DM. Clin
Endocrinol 1979;10:39-45. Possible cancer hazard associated with
5-methoxypsoralen in suntan preparation

SIR,-I would like to support Professor $M$ Ashwood-Smith's letter (3 November, p 1144) on the potential hazards of including psoralens in suntan preparations.

All psoralens that have a photosensitising effect enhance the DNA damage caused by ultraviolet light, as admitted by Dr P Forlot in his reply ( 1 March, p 648). This increased "injury" is perhaps acceptable in psoriatic patients, who may by virtue of their disease have an increased resistance to mutagenesis, but is not so in normal fair-skinned individuals, who have a limited ability to tan and rely heavily on the protective qualities of suntan preparations to allow them to disport themselves in the sun at all.

It seems completely unjustified with our present knowledge to expose this highly susceptible group to a substance that has been clearly shown to be mutagenic. If photosensitisers must continue to be added to suntan preparations at least let the containers be clearly marked as such so that the choice rests with an informed public.

Peter Kersey

Dermatology Department,

Royal Victoria Infirmary

Newcastle upon Tyne NE1 4LP

SIR,-The letter of Dr P Forlot (1 March, p 648) concerning the use of 5-methoxypsoralen in suntan preparations requires some comments.

So far as we know, the 5-methoxypsoralen in suntan preparations is used in the form of natural oil of bergamot and not as a pure chemical, according to the actual EEC regulations. From the point of view of the chemical itself, the mutagenic effects of 8-methoxypsoralen and 5-methoxypsoralen have been studied in vitro by Pool et $a l^{1}$ and Hoffnung et al (unpublished observations). 8-Methoxypsoralen and to a lesser extent 5-methoxypsoralen have yielded a weakly positive reaction in the Ames test, this reaction being comparable with that of caffeine.

Our statistics for a single PUVA therapy centre (where over a four-year period 1359 patients have been treated with 8-methoxypsoralen $^{2}$ ), the results of the French national survey carried out over this same period for 4000 patients, and the European statistical study of 3000 patients (Christophers, personal communication) have all yielded results different from those of Stern $^{3}$ in that no case 
of cutaneous cancer attributable to PUVA therapy was reported.

Finally, the epidemiological study carried out in the bergamot-oil-producing area of Calabria on subjects in contact with the oil has shown no oncogenic effects of the natural substance (Mezzadra, unpublished observations). Studies currently under way (Magnus, personal communication) have shown that one of the incriminated suntan solar products is not carcinogenic after more than 26 weeks' irradiation of the hairless mouse with a solar simulator under conditions far more drastic than those encountered by the normal holidaymaker.

In view of the current state of our knowledge, we feel that these data justify rejection of the hypothesis of any risk of cancer due to PUVA therapy, although we do recommend that vigilance is maintained. As for the use of 5-methoxypsoralen in suntan preparations, we feel that, considering the current data and the very low concentration of 5-methoxypsoralen in this type of preparation, the episodic character of exposure to ultraviolet rays, and the fact that these products all contain an efficacious ultraviolet filter, the risk may be considered very low compared with the potential benefits.

Charles Grupper BRUNO BERETTI

Service de Dermatologie, Polyclinique d'Aubervilliers,

93300 Aubervilliers,
France

12 Pool BL, et al. Arztl Kosmetol 1979;9:349. Academy of Dermatology, 1979.

3 Academy of Dermatology, 1979. et al. N Eng $\mathcal{F}$ Med 1979;300:809-31.

\section{ECT: balancing risks and benefits}

SIR,-Dr P E Bebbington and his Maudsley colleagues (15 March, p 792) may disagree with Professor D A Pond's eminently sensible letter about unmodified ECT (9 February, p 403) but they offer no arguments to rebut the reasons he gives for its possible use. Psychiatrists who work in less favoured parts of Britain will be more likely to know of situations in which it would constitute the best available practice. Professor Pond says that it might be urgently needed to "control the patient's behaviour." Would his critics have felt less hostile if he had said "to relieve a patient's intolerable depression"?

Those privileged to work in "centres of excellence" should be careful not to nudge us further down the already alatming slide into "defensive medicine."

JAMES MATHERS

Hay-on-Wye,
Hereford HR3 5 DQ

\section{Tinted visors and the hazard to motorcyclists}

SIR, - The possible hazards of driving while wearing tinted lenses were the subject of correspondence in these columns in 1976 (starting on 15 May and ending 23 October). Since then the revision of British Standard 4110 has been completed and the new version, Eye-protectors for Vehicle Users issued. Only clear materials will satisfy the new version of this standard.

The Road Traffic Act requires that when a protective helmet is sold to a motorcyclist it shall comply with the relevant British Standard. By the end of this summer recent amendments to the helmet standards will require that if a helmet is sold complete with a visor then that visor must also comply with the relevant standard. However, visors sold separately, or as replacements to original clear visors, do not come under the Road Traffic Act. They could possibly come within the compass of the Consumer Safety Act were a Regulation to be made under this Act.

Unless action is taken to make all new visor comply with BS 4110/1979, motorcyclists will continue to buy tinted visors whose density and colour are subject only to the whim of fashion. These are being used at night when a rider's life may well depend on his ability to see the potholes in our deteriorating roads and obstructions lying in the carriageway.

\section{Department of Optometry and Visual Science,}

J B DAvEY

City University,

\section{Sorrows of dying}

SIR,-Your leading article (1 March, p 592) on questions of dying repeats current attitudes towards the subject which leave one wondering whether much of the agonising is not misplaced. It is taken as axiomatic that the process of dying is sacrosanct. Relief of the suffering of dying is allowed but never its complete elimination, even at the express wish of the dying person. A clean break from life to death is forbidden. Drift and the operation of force majeure is at present the only acceptable method of dying.

Must this attitude remain for ever unchallenged by a more enlightened view, which sees a voluntarily accepted rapid transition as eminently desirable both for the sufferer and for those who minister to his needs? Safeguards there must be but surely some consideration must sooner or later be given to the continuing demand of at least $5 \%$ of dying persons for legalised euthanasia.

Huddersfield

\section{$S$ L HeNDERSON SMith}

\section{Topical corticosteroids on the face}

SIR,-Dr K D Crow (23 February, p 572) does not accept that $2 \frac{1}{2} \%$ hydrocortisone is any more likely to cause perioral dermatitis than the $1 \%$ concentration suggested in your leading article (19 January, $p$ 136). An assumption of equivalent safety despite the higher concentration is entirely justified on pharmaceutical grounds since the additional $1 \frac{1}{2} \%$ hydrocortisone, being totally in suspension, would only provide a marginal increase in pharmacological activity. Clinical experience has confirmed that, in ointments, increasing the concentration of hydrocortisone above $1.0 \%$ without altering the base provides no increase in therapeutic activity. ${ }^{1}$

In order to maximise the partition coefficient for significant bioavailability, the hydrocortisone should be present in molecular solution. This has been confirmed by the fact that a cream formulation containing only $0.1 \%$ hydrocortisone in solution (Dioderm) has been shown to be more active than $1.0 \%$ hydrocortisone cream $B P C$, where most of the hydrocortisone is in suspension. ${ }^{2} 3$

The increased potency of synthetic corticosteroids derives mainly from the protection of the molecule against oxidative degradation of the 17-tertiary alcohol by epidermal enzymes. ${ }^{4}$ This
$\mathrm{OH}$ group may be converted into an ester (for example, betamethasone 17-valerate, hydrocortisone 17-butyrate) or an ether (for example, triamcinolone 16,17-acetonide) or removed altogether (for example, diflucortolone 21-valerate), with the result that pharmacological activity is enhanced dramatically, partly because of increased lipoidal solubility but mainly owing to resistance to local metabolism. In consequence of the latter, synthetic topical corticosteroids have to be transferred to the liver for metabolism. Since this is a slow process owing to low water solubility, they can remain in the epidermis for up to two weeks, as evidenced by the vasoconstriction which appears on reocclusion of the treated site. ${ }^{5}$ As the frequency of application to the skin normally exceeds the rate of transportation, a local reservoir builds up, producing the well-known side effects.

It is not justifiable only to indict the presence of fluorine in the molecule, and any criticism of fluorinated steroids that does not include all other corticosteroids which lack a free $17-\mathrm{OH}$ group insidiously disguises the root of the problem. It has now been confirmed that hydrocortisone butyrate, which differs from hydrocortisone only by the presence of a 17-ester, behaves just like the fluorinated corticosteroids, especially as it can cause perioral dermatitis ${ }^{6}$; and the original claims of safety for use on the face ${ }^{7}$ have now been withdrawn. ${ }^{8}$ This is in complete contrast to the accumulating evidence of the mildness of naturally occurring hydrocortisone ${ }^{9}$ - which does not, of course, form a reservoir in the epidermis. ${ }^{2}$

MARTIN Whitefield

Dermal Laboratories Limited,
Hitchin, Herts SG4 7QR

${ }^{1}$ Kranz G, Schaefer H, Zesch A. Acta Derm Venereol

(Stockh) 1977;57:269-73.
2 Barry BW, Woodford R. Br f Dermatol 1976;95: 423-5. 92:585-8. Greaves MS. F Invest Dermatol 1971:57:100-7. 5 Vickers CFH. Arch Dermatol 1963;88:72-5. 6 Cotterill JA. Br f Dermatol 1979;101:259-6. : Sneddon IB. Br ₹ Dermatol 1973;89:505-8. ${ }^{8}$ Sneddon IB. Br f Dermatol 1980;102:239-40 ${ }^{9}$ Sneddon IB. Br Med f 1969 ;i:671-3.

\section{Exercise training in chronic bronchitis}

SIR,-I read with interest the article by Drs D J M Sinclair and C G Ingram (23 February, p 519). For the last three years it has been our routine practice to start patients with severe chronic bronchitis and minimal exercise tolerance on walking exercises using a Zimmer-type pick-up aid (pulpit). Immediately on recovery from the acute exacerbation of the condition exercise is continued under regular supervision in the day hospital or outpatient physiotherapy clinic for approximately three months.

We use as a baseline the maximum distance that the patient can walk without undue respiratory distress without using an aid. In our elderly severely affected "respiratory cripples" this distance is commonly only 5 or $6 \mathrm{~m}$ with encouragement. Using an aid with the height adjusted to the level of the styloid process of the ulnar, most patients can double their baseline distance immediately, but encouragement is essential as these patients are convinced that they are unable to walk more than a few steps. A personal diary card records approximate improvement in walking distances. By three months many patients record improved walking distances, confirmed by the trained therapist, of five to ten times the original baseline distance. Respiratory function tests are only carried out for general inpatient management or for 